\title{
EDUCAÇÃO A DISTÂNCIA E COMUNICAÇÃO: PERCEPÇÕES DA FORMATAÇÃO DO PERFIL DOCENTE E DISCENTE
}

https://doi.org10.29327/3860.11.20-4

\author{
Adeilton Santana Nogueira ${ }^{1}$ \\ Andrea Karla Nunes ${ }^{2}$ \\ José Gomes da Silva ${ }^{3}$
}

\section{RESUMO}

Em meio às novidades tecnológicas os atores humanos são os principais recursos que a Educação dispõe. Ora o protagonismo estará no tecnólogo ora no professor ora no aluno. Todavia, destaca-se neste artigo científico a sagacidade de perceber que a modalidade Educação a Distância $(\mathrm{EaD})$ está formatando o perfil desses agentes e da Educação. Para a apresentação desse processo, utilizamos como base uma metodologia de revisão de literatura, onde aplicamos algumas Teorias da Comunicação, sobretudo as ideias de McLuhan (1969; 1972), Keen (2012) e Pariser (2013), com as preocupações dos educadores, como Mill (2010) e Santaella (2013), numa confluência sugerida aqui como condicional do sucesso da Educação a Distância e desenho da sociedade e, consequentemente, do perfil do professor e do estudante. Portanto, este artigo, tem como objetivo discutir enlaces entre as áreas que fundamentam os saberes técnicos e teóricos da $\mathrm{EaD}$, a Comunicação e a Educação, perfilando o docente da contemporaneidade com ambas competências e habilidades, ou suas necessidades. Como resultado apresentamos a consequente formatação do perfil comunicador do docente pari passu da necessidade de uma formação adequada desde a licenciatura, entretanto que contemple aspectos da Educação nas demais graduações que atualmente lhe dão suporte, sobretudo técnico.

Palavras-chave: Educação a Distância; Comunicação; Formação de professores; Docência.

\section{DISTANCE EDUCATION AND COMMUNICATION: PERCEPTIONS OF THE FORMATION OF THE TEACHER AND DISCIPLE PROFILE}

\begin{abstract}
In the midst of technological innovations human actors are the main resources that Education has. Sometimes, protagonism will be in the technologist, sometimes in the teacher and sometimes in the student. However, this scientific article emphasizes the

\footnotetext{
${ }^{1}$ Mestre em Educação (linha 1 - Educação e Comunicação), Universidade Tiradentes - UNIT/SE. Pesquisador no Grupo de Estudos em Tecnologias da Informação e Cibercultura - UNIT/GETIC

${ }^{2}$ Mestrado e Doutorado em Educação da Universidade Tiradentes, da linha 1 - Educação e Comunicação - PPED - Universidade Tiradentes - UNIT - SE

${ }^{3}$ Doutor e Mestre em Educação pela Universidade de Salamanca (ESP). Professor investigador na Universidade Tiradentes - UNIT - PNPD.
} 
ability to perceive that the Distance Education modality is shaping the profile of these agents and Education. For the presentation of this process, we used as a base a literature review methodology, where we applied some Communication Theories, especially the ideas of McLuhan (1969, 1972), Keen (2012) and Pariser (2013), with the educators concerns such as Mill (2010) and Santaella (2013), in a confluence suggested here as conditional on the success of Distance Education and society's design and, consequently, the profile of the teacher and the student. Therefore, this article aims to discuss links between the areas that support the technical and theoretical knowledge of Distance Education, Communication and Education, outlining the decent of contemporaneity with both skills and abilities, or their needs. As a result we present the consequent formatting of the communicator profile of the teacher pari passu from the need of an adequate training since graduation, however that contemplates aspects of Education in the other graduations that currently support him, mainly technical.

Keywords: Distance Education; Communication; Teacher training; Teaching.

\section{INTRODUÇÃO}

O modo como o professor ministra a sua disciplina e os recursos materiais ou digitais que leva para sua aula, toma uma forma diferenciada, sobretudo quando se trata de Educação a Distância - EaD. O modus operandi do professor recebe uma nova caracterização, diversos componentes, aparentemente não didáticos, que já foram vistos com receio, temor e até distração, mas já conquistaram o seu espaço na escola, a saber, as tecnologias digitais.

As Tecnologias de Informação e Comunicação - TIC realizaram recentemente aquilo que suas predecessoras iniciaram, elas ingressaram em massa na classe. Tiraram o professor da sala de aula convencional, mas não o substituíram. Também tiraram o aluno, enquanto virtualizavam as paredes das instituições de ensino.

Não raro as TIC realizam o sonho de todo professor, que é o aluno estudar em casa. Não somente em casa como em qualquer lugar. Isto se deu simultaneamente nos tempos em que a informática subiu para as nuvens e os serviços aqui em baixo se tornaram ubíquos $^{4}$, ou seja, fornecidos independentemente da localização do cliente.

\footnotetext{
${ }^{4}$ Ubíquo ou ubiquidade "significa ser encontrado em todo lugar" (PAVLIK, 2014). É a presença constante das mídias e tecnologias móveis, a qualquer hora e em todos os lugares, de forma onipresente e pervasiva, que disponibilizam o acesso imediato da informação, seja por recepção ou por sua produção e distribuição, mediante conexões com ou sem fio.
} 
Desta forma atentemos aos dados do Comitê Gestor da Internet do Brasil (CGI.br, 2017), na pesquisa TIC Educação 2016, de abrangência nacional, com instituições públicas e privadas respondentes, sendo 935 escolas, 935 diretores; 922 coordenadores pedagógicos; 1.854 professores e 11.069 alunos.

A pesquisa apresenta em seus principais resultados que, em 2016, 99\% das escolas pesquisadas possuiam acesso à Internet, da qual $82 \%$ em sala de aula. Quanto a usar o telefone celular para atividades pedagógicas a pedido dos professores, $61 \%$ dos alunos da rede pública e $60 \%$ da rede particular afirmaram positivamente. O computador de mesa continua prevalecendo em $98 \%$ das escolas, entretanto se evidencia um crescimento relevante dos dispositivos portáteis, sendo $86 \%$ nas escolas públicas e $92 \%$ nas escolas particulares, contra os $67 \%$ e $64 \%$, respectivamente, na mesma pesquisa de 2011.

É consenso da maioria dos alunos, segundo a pesquisa TIC Educação 2016 (CGI.br, 2017, p. 101) que, em primeiro lugar, "quando o professor usa a internet a aula fica mais legal”; em segundo, "eu aprendo mais fácil", dizem os alunos, e em terceiro "eu presto mais atenção na aula". O que não se diferencia da percepção das facilidades também apontadas pelos diretores, coordenadores e professores, quanto ao uso da Internet em seus trabalhos.

Outro fator pesquisado diz respeito à oferta da conexão contínua, que afeta a educação $\mathrm{e}$, consequentemente, inaugura outras formas de aprendizagem, mediadas pelos dispositivos $^{5}$ móveis. Destarte, em tempos de ubiquidade também encontramos estudantes híbridos. Quem faz algum curso presencial pode estar em qualquer lugar, conectado ou não, estudando com dispositivos móveis. Inclusive, na 'Internet de pessoas ${ }^{6}$.

Um novo cenário se descortina nos processos educacionais. Enquanto não se encontra uma pedagogia única que responda, norteie ou assegure o dueto ensino aprendizagem, vão se multiplicando, enquanto se descobrem, novas formas de aprender. Talvez o diferencial pedagógico desta Era digital seja as múltiplas formas de fazer Educação.

\footnotetext{
${ }^{5}$ A ideia de dispositivo trabalhada neste artigo está fundamentada em Agamben (2005), quando parte das obras de Foucault que evidenciam a terminologia de positividade e possibilidade, como ação de poder fazer; não uma tecnologia específica, mas o enredamento que possibilita a sua adesão e eficácia. Logo, o objetivo de um dispositivo, segundo Agamben (2005, p. 11) é "fazer frente a uma urgência e de obter um efeito", com êxito.

${ }^{6}$ Expressão de Dixon (apud KEEN, 2012, p. 10).
} 
Consideramos também outra pesquisa recente, o censo realizado pela Associação Brasileira de Educação a Distância (Abed), EaD.BR 2017, quando traz uma inclusão nova, inserida desde o Censo EAD.BR 2016, conforme justificativa da Abed (2017), por terem observado em 2015, que as questões pedagógicas estavam preocupando os gestores de EaD. Desta vez, quando foi perguntada a opinião dos respondentes acerca dos desafios da $\mathrm{EaD}, 8$ das 9 afirmações mais concordantes, encabeçam a lista das exigências, com a inovação em abordagens pedagógicas.

O censo acima constata que a maior dificuldade em EaD não se trata de inovação tecnológica, inovação de processos administrativos, alto padrão de infraestrutura, contratação de profissionais capacitados, formação contínua, desenvolvimento de estrutura de apoio aos alunos e estrutura administrativa complexa, nessa ordem segundo o Censo EAD.BR 2017 (ABED, 2017, p. 69), mas esta lista é encabeçada pela afirmação de que a EaD "exige inovação em abordagens pedagógicas".

Dito desta forma, considere-se a atual condição multi e transmidiática da Educação, arrancando-a das mãos de quem quer que pretenda defini-la, salvo o fato de que a Educação continua fluindo para e nas mãos dos estudantes. Hoje, mais do que antes, pela sua condição social e localização econômica, os saberes e a informação são flutuantes e democráticos.

A distância, antes geográfica, vencida pelas tecnologias, denuncia um novo estilo de vida. Prova-o a estrutura EaD, quando proporciona ao aluno independência sem isolamento. Contudo, se sua teoria filosófica e pedagógica estiver mais voltada ao produto e não ao aluno, não contribuirá com a pessoalização deste, embora a plataforma se apresente personalizada. Logo, destaca-se neste artigo a percepção de que a modalidade $\mathrm{EaD}$, pelo seu corpo mecânico e sistemático, está formatando o perfil desses agentes e da Educação como um todo.

Isto posto, discutimos ao longo deste artigo, onde utilizamos a metodologia de revisão de literatura, aplicando algumas Teorias da Comunicação, sobretudo as ideias de McLuhan (1969; 1972), Keen (2012) e Pariser (2013), com as preocupações dos educadores, como Mill (2010) e Santaella (2013), numa confluência aqui sugerida como condicional do sucesso da $\mathrm{EaD}$, do desenho da sociedade e, consequentemente, do perfil do professor e do aluno. Portanto, este artigo, tem como objetivo discutir enlaces entre as áreas que fundamentam os saberes técnicos e teóricos da $\mathrm{EaD}$, a Comunicação e a 
Educação, perfilando o decente da contemporaneidade com ambas competências e habilidades, ou suas necessidades.

Perguntamo-nos o que a Comunicação tem a dizer à Educação. Sabemos que, dada a amplitude deste intento, não arriscamos alguma resposta em definitivo, apenas contribuímos com tal diálogo. Assim promovemos a pesquisa e a própria ciência, com suas inquietações. Logo, trazemos neste artigo uma perspectiva simbiótica do estado da educação na Internet.

\section{EAD, ECONOMIA E SOCIEDADE}

A reflexão que pretendemos não é desconhecida. Trata-se do encontro das duas áreas: Educação e Comunicação que, na modalidade da $\mathrm{EaD}$, vem mostrando sua maior confluência, chegando a influenciar e determinar a hibridez do ensino presencial.

Desde já, destacamos dois fatores que contribuíram para o crescimento do ensino a distância e tencionaram o seu destino: primeiro as TIC e suas múltiplas e contínuas transformações, aliadas ao segundo fator, o perfil dos usuários das mídias de transmissão (e produção) e seus usuários (os internautas). Ambos se tornaram como que pulmões que renovam constantemente o ar que revitaliza o novo sistema do ensinoaprendizagem.

Mas estes pulmões tem um novo coração, por onde fluem todos os saberes e conhecimentos e, sem dúvidas, o comparamos à Internet. Apenas nisto discordamos de Keen (2012, p. 40), quando o chama de cérebro.

A internet que antes era um canal de distribuição de informações impessoais, hoje é uma rede de empresas e tecnologias, concebida em torno de produtos, plataformas e serviços sociais - transformando-se, de uma base de dados impessoal, num cérebro digital global que transmite publicamente nossas relações, intenções e nossos gostos pessoais.

Na sequência, o autor acima acrescenta que a internet pretende ser o coração digital da humanidade, não apenas do internauta. Logo, em meio às preocupações de uma provável antropologia digital, recaímos sobre o estudante destinatário da $\mathrm{EaD}$, "foco e centro do processo educacional", como afirma o Ministério da Educação (BRASIL, 2007, 10). 
Ademais, há outros aspectos da expansão tecnológica que nem sempre nos atinamos ao achar que, no uso das TIC e da Internet, tudo se trata de benefício e valorização da educação. O que se mostrará um avanço empreendedor e desafiador do processo educacional, porém cauteloso, sobretudo quanto ao foco demasiado no pessoal, nos gostos e hábitos do usuário da Web. Informações pessoais que, segundo Keen (2012, 46), "são o ingrediente fundamental, o combustível revolucionário que alimenta a economia da Web 3.0".

O comunicólogo acima ainda se refere ao eufemismo de Horowitz (apud KEEN, 2012, p. 46), do Google, em chamar esta estratégia de colocar "as pessoas em primeiro lugar". Logo, há outras preocupações no background do palco tecnológico que nos chamam a atenção para o lado capitalista da World Wide Web, WWW, a teia do tamanho do mundo.

A Web de hoje é a Web 3.0; a Web semântica que Santaella (2013, p. 45) define como sendo aquela que "trabalha com a atribuição de significados aos termos utilizados nos motores de busca, de modo a satisfazer a intenção de cada usuário quando busca uma informação e espera receber uma resposta que seja tão precisa quanto possível". Aquilo que parecia uma metodologia didática de personalização do ensino, agradar o usuário, aparece aqui como uma estratégia de negócios dos gigantes da Internet.

Neste aspecto temos em mente o que diz o vice-presidente do Yahoo, Tapan Bhat (apud PARISER, 2012, p. 13), quando concorda com a diretora executiva de operações do Facebook, Sheryl Sandberg, ao afirmar que "O futuro da internet é a personalização - a rede agora gira em torno do 'eu' ". Ao que parece, na medida em que a internet entra na escola a educação é quem vai assimilando as suas propriedades. Mas isto é bom ou ruim?

Ainda, consentimos no que McLuhan (1972) diz, ao traçar a galáxia de Gutenberg, se o advento da palavra impressa foi boa ou não. Sua preocupação também é a nossa e a aplicamos à nova e atual forma digital de ler, escrever e entender: "o de que a inconsciência do efeito de qualquer força constitui um desastre, especialmente quando se trata de forças que nós mesmos criamos". Sobretudo se não as conhecemos nem as dominamos.

Estamos numa revolução sem precedentes, o mergulho da sociedade na Internet (GABRIEL, 2013), que não pode ser às escuras. É grande o número dos que se 
aventuram nessa odisseia sem volta. De acordo com Negroponte (apud WERTHEIM, 2001, p. 21), se a taxa atual de crescimento se mantiver, "o número total de usuários da Internet ultrapassaria a população do mundo" no início desse século.

Todavia, o otimismo exagerado acima não correspondeu às expectativas de Blum (2015, p. 176), Presidente da Comissão de Estudos de Tecnologia e Informação do Instituto dos Advogados de São Paulo, quando declarou que "até o final do ano de 2014, haverá mais de três bilhões de usuários da Internet, sendo dois terços oriundos de países em desenvolvimento. E esse mercado tem muito a crescer, visto que quatro bilhões de usuários não usam internet”. Apesar de ambos pesquisadores não igualarem seus dados, vale perceber que se referem a bilhões de usuários, com diversas contas de acesso e de tantos outros bilhões em potencial.

Quanto a nós, não nos enganemos, não são as pretensões paradisíacas do ciberespaço (WERTHEIM, 2001) ou o acaso do progresso espontâneo tecnológico que o torna tão desejável, mas um investimento de manipulações econômicas que a instituição escola não se furtaria. Não descuremos que, embora fosse fundamental para o crescimento da sociedade, a educação também foi usada por ideologias dominantes em seu processo.

O que se prega na sala de aula ou fora dela não é alheio ao mundo, parte, no entanto, da concepção de sociedade e do seu modelo mercadológico. Isto não ocorreu apenas no passado. O que chega à escola vem da sociedade em que nasce, não obstante, com a formatação da indústria e comércio. Sinos e sirenes, cronogramas, avaliações ainda estão presentes na prática escolar, assim como o seu positivismo e fordismo ainda exercem o poder de tornar a escola um ambiente dócil e progressivo.

Até a matriz curricular estará a serviço da pessoa que se quer moldar na sociedade, o profissional que queremos, por uma ideologia vigente, definindo o que é importante para o aluno aprender. Pois, onde se define uma concepção de sociedade, a Educação não é uma ação neutra. O planejamento de uma aula dependerá de alguma ideologia e da própria concepção que o educador tem de sociedade e Educação. Logo, a Educação passou a ser digital porque toda a vida pessoal e social se conecta em rede. Não há como ficar fora disso, segundo comenta Keen (2012, p. 58):

Como argumentam os pregadores digitais [...]. Estamos entrando no que eles chamam de "era da inteligência em rede", uma mudança histórica "grandiosa", [...] uma "plataforma para as mentes 
operando em rede" que nos permitirá “cooperar e aprender coletivamente.

Não tão distante, posterior ao religioso medieval e científico moderno, o período em que a sociedade esteve mergulhada no universo industrial, a Educação incorporou suas características, de modo que, ainda hoje vemos as escolas e sistemas letivos submetidos às linhas de montagem e produção, como se fossem fábricas, onde o produto é a mão de obra competente e especializada. O modelo industrial da educação, todavia, não se sustenta mais sozinho porque correspondia à sociedade da época.

A subdivisão de tarefas na $\mathrm{EaD}$ abre espaço a outros tipos de atividades, na qual o professor não é mais um artesão, mas uma parte do sistema. A teoria da $\mathrm{EaD}$ é volátil porque o tempo presente é marcado pela mobilidade e fluidez (BAUMAN, 2001). Porém estávamos acostumados a viver 'em caixinhas departamentais', assim como as disciplinas eram, embora atualmente sejam menos, ministradas sem preocupações interdisciplinares. Contudo, entramos no olho do furacão dessas mudanças ao compreendermos o que nos diz Keen (2012, p. 119):

[...] a revolução digital foi causa principal e efeito de outra profunda mudança estrutural na paisagem econômica - a transição de uma economia dominada por monopólios industriais $[\ldots]$ para uma economia muito mais individualizada, moldada pelo que Peter Drucker, o influente teórico da administração no século $\mathrm{XX}$, definiu como economia do "conhecimento" e da "informação.

Este comunicólogo destaca que a transformação de que fala Drucker (apud KEEN, 2012) de que a economia de produção industrial, baseada no comércio, para a economia dominada pela troca de informação, apresenta uma mudança do "centro de gravidade" do fabricante ou distribuidor para o "consumidor". E acrescenta: "O livre-mercado de amanhã", para Drucker (apud KEEN, 2012, p 120), "significa fluxo de informação, e não de comércio". Se revisássemos a linha histórica da educação ficaria mais claro o quanto a educação singra o mar da sociedade, cujos ventos sopram, de tempos em tempos, por forças econômicas, políticas e até religiosas.

Apesar de todas essas influências e interferências concordamos com Dias e Leite (2010, p. 17) de "que a educação, independente da modalidade, não é um produto, mas um processo e, portanto, nunca se termina de aprender". É processo justamente por seguir 
os vieses econômicos e sociais, consequentemente educacionais. Esta reconfiguração das práticas educacionais é vital para sua utilidade e propósito social.

Só não sejamos ingênuos, pois há muitos produtos e muito de produtivo na Educação. Porém, não podemos deixar que ela se torne apenas isso. O ser humano é transformado pelas tecnologias, mas também é seu criador e ela está em função da humanidade. É o uso que fazemos dos aparatos tecnológicos em nossas mãos que lhes dá o destino e define o nosso presente (KEEN, 2012), logo, não há bondade ou maldade na técnica, há usabilidade.

Não é pequena a herança da industrialização e do comércio na Educação, bem como há compra e venda no EaD (COSTA; AQUINO, 2011/2), mesmo que seja do processo e não do ensino. A EaD figura um produto industrializado; a produção de uma aula multimidiática é o fim de uma linha de montagem de muitas mãos. Outrossim, a proposta de muitos Projetos Políticos Pedagógicos tem sido mais metodológica e técnica e nem sempre temos clara a pedagogia e filosofia de ensino (FONTANA, 2006), sobretudo quando o foco está no produto.

Já que falamos de produto, discorreremos agora daquilo que o produz: o processo. $\mathrm{O}$ discurso e o debate sobre a pedagogia da comunicação. O perfil dos gestores de ensino, o perfil docente, são questões que precedem o processo e como ele acontece pois, para que ocorra, o foco precisa estar na forma como essa modalidade de ensino acontece.

Sabe-se da metafísica aristotélica que a forma não é o contínuo de atividades chamadas de processo, mas 'a ideia que o escultor imprime no mármore'. Sem a ideia jamais se transformaria o mármore, aquilo que usualmente nos referimos à forma de fazer, pensando em procedimentos, mas na verdade deveríamos pensar nas ideias que dão forma às coisas.

Acreditamos que quando olharmos a $\mathrm{EaD}$ contemplando todo o seu potencial, aquilo que podemos fazer dela, e trabalharmos em razão dessas concepções sairemos do automatismo de nossa produção.

\section{As mídias, a personalização e o perfil polidocente}

Desde a década de 1930, com a Escola Nova, a Educação tirou a centralidade do professor para olhar mais para o aluno. No Brasil, aquele era o contexto militar de formação do cidadão operário, herança histórica muito presente ainda hoje nas escolas. 
Entretanto, as atuais preocupações com a nova modalidade de ensino, ainda mais exigentes que a presencial, revisa o lugar do professor e traz questões semelhantes às humanísticas da escola tradicional. Antes o professor era enciclopedista, detentor do máximo de conhecimento possível, agora é conteudista. O diferencial é que desta vez o educador possui diversos aparatos e formatos tecnológicos digitalizados. $\mathrm{Na} \mathrm{EaD}$ o professor faz download e se atualiza, mas também faz upload e atualiza a rede de informações.

O perfil do professor EaD não está relacionado apenas aos alunos, mas ao tipo de mídia em que ele atuará a sua disciplina, o local da aula, em cujo cenário e com quais recursos tecnológicos. Este dado novo, as mídias, definirá a sua postura, competências e habilidades específicas, semelhantes àquelas do profissional da comunicação que o assessora, ou não. Em outras palavras, não é apenas o tipo de aluno, idade ou região para qual é produzida/ ministrada a disciplina, mas o aparato tecnológico que o media e do qual ele faz parte que induzirá o professor aos recursos, posturas e linguajar adequados.

Vale trazer para este diálogo McLuhan (1972), segundo o qual a criação da prensa de tipos móveis foi a real precursora das mudanças sociais, quando multiplicou os livros copiados nas mãos da Igreja, inclusive a Bíblia, e popularizou o conhecimento e a informação. Inclusive, Zavam (2013) testemunha que o material didático só passou a compor o cenário de uma sala de aula a partir daquele invento.

McLuhan (1972) continua que tal acesso promoveu a leitura e à revolução do pensamento europeu, ao passar das pinturas católicas à alfabetização e ao iluminismo. Para este autor foi a saída do mundo auditivo-comunitário para o visual-individual que colocou o homem nas linhas de produção industrial.

$\mathrm{O}$ autor acima ainda se admira de que nem os filósofos perceberam que tais mudanças históricas não decorreram das grandes ideias, mas dos meios pelos quais foram transmitidas. Sobre Heidegger, por exemplo, a quem estima, McLuhan (1972, p. 305) afirma: "parece ignorar completamente o papel da tecnologia eletrônica em promover o seu próprio modo de ver a linguagem e a filosofia como fenômeno global "não-letrado" ”. McLuhan (1972) destaca ainda que, em sua época, Gutenberg não tinha sido levado a sério, a fim de que aplicassem seus postulados a ordenação da vida. Mutatis mutandis, não cometamos o mesmo engano. 
Decerto que a história das mídias não previa a internet. Em sua tese da Aldeia Global, McLuhan (1969), por meio da televisão, ganhou um impulso ainda maior. Mas, este tambor comunitário foi potencializado pelo advento da Internet. Se para Mcluhan (1969) o meio é a mensagem, para Flusser (1985) nos tornamos a mídia que utilizamos. Conceitos que se agravam em "o código é a lei”, de Pariser (2012, p. 23), que indica serem os codificadores dos dispositivos da Web programadores da personalização à qual aderimos pelo uso.

Então as mudanças que os meios de comunicação provocaram no passado, aparentemente sem intencionalidade, agora são programadas. Pariser (2012, p. 23) alerta:

Se o código é a lei, como na famosa declaração de Lerry Lessing, é importante entendermos o que os novos legisladores têm em mente. Precisamos entender aquilo em que acreditam os programadores do Google e do Facebook. Precisamos entender as forças econômicas e sociais que movem a personalização, algumas delas inevitáveis, outras não. E precisamos entender o que tudo isso representa para nossa política, nossa cultura e nosso futuro.

De fato, como atesta Wertheim (2001, p. 21) "As pessoas não adotam uma tecnologia simplesmente porque ela existe". A autora relaciona essa adesão à consonância com um desejo latente, cuja essência precisa de explicação, fato pelo qual: "Precisamos compreender quais são os fatores que geram um interesse tão intenso por essa tecnologia particular" (WERTHEIM, 2001, p. 22). Esta compreensão aprimora a aplicabilidade das TIC segundo o uso e interesse que causa em seus usuários.

A personalização das redes utiliza das tecnologias inteligentes (LÈVI, 1990), onde, segundo o exemplo de Negroponte (apud PARISER, 2012, p. 25 - 26), “A chave para o futuro da televisão [...] é pararmos de pensar a televisão como uma televisão". Este último sugere pensarmos nela (a televisão), ou qualquer outra mídia, como elucida Pariser (2012, p. 26): “como um aparelho com inteligência”. Isto, por pensarem conosco e até por nós.

A questão é que cada mídia na era da personalização deverá ser capaz de atender ao máximo de solicitações, necessidades e gostos do usuário. O sistema é o seguinte: A nova ordem digital toca no fundamento da inteligência que é a memória e a sua capacidade de armazenamento e codificação para o acesso às lembranças. Uma coisa 
simples, como voltar ao lugar onde esquecemos algo, traz de volta aquela lembrança. Imagina que a personalização faz isto mesmo. Como nos explica Santaella (2013, p. 4546):

\begin{abstract}
As respostas chegam, sem que tenhamos que memorizá-las. Basta saber voltar ao lugar virtual em que elas se encontram. A plasticidade implicada na rápida adaptação da memória humana a esses novos recursos e procedimentos cognitivos está nos tornando simbióticos com nossos computadores [...] que nos levam a saber menos sobre o conteúdo específico das informações em contrapartida com o muito que passamos a saber, graças a essa simbiose, sobre onde as inumeráveis versões das informações se encontram.
\end{abstract}

A esta altura alguém está se perguntado, mas o que isto tem a ver com o perfil do professor EaD? A pergunta deveria ser outra: Personalização ou bolha invisível? Pois é justamente essa recodificação que está configurando todos os perfis sociais.

Graças a este grande extensor cognitivo o usuário da internet, pelo simples fato de acessar a Rede, está fornecendo todos os seus dados e hábitos virtuais. Isto é o que leva a articulista Lafuente (apud SANTAELLA 2013, p. 50) a acreditar que a Web 3.0 mudará "todos os aspectos da vida humana, o modo de operar empresas, a pesquisa e o desenvolvimento, o acesso a produtos e serviços, a informação e a noção de privacidade”. Logo, também podemos nos perguntar: Como ficam a Educação, o professor e os alunos?

A impressão que dá é que navegamos em alto mar. Se nos perderemos ou não a saída é potencializar ao máximo a nossa nau. Nem televisão, como dito acima, nem EaD podem mais ter apenas um formato. O ensino, por exemplo, acontece mesmo sem a Educação; as distâncias não nos afastam. Espaço e tempo são virtuais, tornam-se megadados configuráveis e programáveis (GABRIEL, 2013). A cada entendimento desses percebemos o quanto a Educação e a Comunicação celebram o seu enlace.

O professor da EaD é testemunha desse casamento. Seu trabalho se organiza de forma coletiva, colaborativa e compartilhada com outros profissionais. É a esse organismo "necessário para a realização das atividades de ensino-aprendizagem na EaD”, que Mill (2010, p. 23) denomina de "polidocência". A nosso ver, um perfil herdado da realidade dos profissionais da comunicação, cada vez mais multitarefas.

Mesmo que no ensino presencial haja outros personagens, a exemplo da coordenadoria pedagógica, secretaria e diretoria da escola, no EaD a diversidade de seus atores está nas 
proporções cinematográfica e no formato midiático. No EaD o plano de aula se converte em roteiro de gravação, pois a polidocência, como diz Mill (2010, p. 23), é uma “docência coletiva". Assim, entendemos que, além do polidocente, toda a equipe necessita testemunhar esse enlace das Ciências. Ademais a professora Pesarini (2011, p. 6) destaque que:

Este trabalho se adéqua a uma equipe que tenha em sua formação o entendimento da pedagogia e da andragogia, do uso das tecnologias de informação e comunicação em prol da educação, ou seja, de como o aluno aprende e de como as mídias podem viabilizar na EAD esta aprendizagem.

O perfil do professor EaD não é de uma face apenas, mas de 'mil rostos'. Talvez não tantos, mas reconhecemos o seu perfil no rosto de tantos quantos lhe cooperam numa equipe montada técnica e profissionalmente. Este tipo de docência roteirizada, quando terminam as apresentações letivas, sobe aquela lista de coadjuvantes, os técnicos, sem os quais não haveria êxito alguma. Portanto, valoriza-se um perfil cooperativo.

Se para Mill (2010), em EaD, quem ensina é um polidocente, estamos de igual acordo com Pesarini (2011, p. 12) de que tal identificação vem levando "o professor a se apropriar de novas funções", tais que podem acarretar-lhe o mesmo risco dos profissionais multitarefas da Comunicação, justamente em face de precisarem administrar múltiplas competências.

Dito dessa forma, destacamos uma característica imprescindível no perfil de comunicador do professor $\mathrm{EaD}$, a de estar ainda mais atento aos alunos menos participativos e ser um animador dos seus espectadores, por meio dos recursos que as TIC lhe possibilitam. Tanto o professor quanto o comunicador necessitam da capacidade de oratória e de retórica, atrair atenção e convencimento para o desempenho do seu ofício.

Insistimos, ignore o dito acima e a própria mídia estará fadada a substituição por outra que satisfaça os interesses do usuário, bem como sites, sistemas, programações, formatos, instituições e, fatidicamente, seus membros. A educação e seus profissionais que não expandirem os seus recursos e colocarem à disposição do usuário/aluno/internauta, tenderão a ser substituídos ou deixados de lado e fracassarão. Esta é a ideia de relevância, segundo Pariser (2012), ou seja, criar interesse. 
Mas, não é esta a maior preocupação do ensino, presencial ou $\mathrm{EaD}$, despertar ou criar interesse? A relevância, não está mais estreitamente ligada ao conteúdo, mas ao modo como o programa prende a atenção do usuário. Sobre esta oferta de relevância pessoal, Pariser (2012, p. 28) declara: "Mais do que qualquer outro fator, esse propósito foi o que moldou a internet que conhecemos hoje". Eis por que também molda o ensino e o perfil do professor EaD.

Desde que nasceu, esta modalidade de educação se adapta aos que a preferem. Começou mediante correspondências no período das Guerras Mundiais, em face das dificuldades de tempo e local das escolas, logo depois aderiu ao rádio e à televisão; já foi escrita, sonora e vídeo. Prova de que uma nova mídia não anula a outra, mas a incorpora e expande. Na era digital a $\mathrm{EaD}$ é tudo isso, contudo na nuvem e na rede, sem carteiros, sem rádios, sem televisores, ou melhor, com tudo isto e nas plataformas digitais.

Estas mudanças exigem, para Hargreavez (apud MILL, 2010, p. 59), um aprendizado “constante, flexibilidade e criatividade". Mill (2010, p. 59) acrescente que isso "reflete na formação dos profissionais em todas as áreas de conhecimento. Torna-se relevante alertar que o profissional esperado para atuar na sociedade contemporânea necessita de uma formação qualitativa diferenciada". Assim, é sobre este diferencial formativo que apresentamos algumas considerações e provocações a seguir.

\section{Formação de professores para EaD}

Estamos motivados a promover algum diálogo entre os autores da Comunicação e da Educação, inspirados pelo conselho de Dias e Leite (2010, p. 17) de que "É preciso discutir e propor teorias que embasem novas concepções para a $\mathrm{EaD}$, pois se corre o risco de repetir, em ambientes altamente tecnológicos, as velhas práticas da sala de aula presencial". Onde, conforme Gouveia e Cesar (2009), até mesmo o chat pode se apresentar com características da aula presencial, com diversas intervenções síncronas e dificuldades de demanda, em atender a todas simultaneamente.

O professor e os sistemas sociais, educacionais, digitais ou não, estão conectados. O que toca em um encadeia no outro como as conexões neurais, pois, como vimos, a máquina modifica o operador. Ademais não se pode descurar do fato de que, segundo Pesarini (2011, p. 7) "Se a educação está mudando, para interagir, valorizar e praticar a inclusão de nossos alunos, certamente os cursos que formam nossos professores precisam 
também passar por uma mudança profunda e radical". As mudanças que já estão ocorrendo em nível mundial urgem atingir os profissionais da educação desde a sua formação, pois, como continua a autora, "sem dúvida nenhuma, a educação a distância, vem se transformando em um fato inquestionável” (PESARINI, 2011, p. 6).

A pesquisa TIC Educação 2016 (CGI.br, 2017, p. 113), também apresenta dados sobre a formação inicial dos professores, dos quais menos da metade (43\%) afirmaram ter cursado alguma disciplina específica na graduação sobre o uso do computador e Internet em atividades com alunos. Entre os pedagogos a proporção é de 38\%, mas diminui para $25 \%$ entre os que cursaram licenciatura em Letras. Índices que se assemelham na formação continuada em serviço, onde $34 \%$ dos educadores, tanto de escolas públicas quanto particulares, realizaram algum treinamento sobre o uso do computador e Internet nos 12 meses anteriores à pesquisa.

Consideremos que o perfil do professor egresso configurará o perfil do aluno em formação e da própria EaD. Todavia, não existe uma hierarquia nesta ordem, onde as ramificações se aglutinam de volta, pois não importa quem vem primeiro, depois que se desencadeiam essas mitoses e meioses letivas. A partir da práxis utilizada todos descobrirão outra forma de estudar, de ensinar e de aprender, de ver o mundo, de capturar o saber acessível e útil; farão escolhas, acertarão, errarão, mas seguirão com sua aprendizagem, vez que os conteúdos são cada vez mais acessíveis e disponíveis em Rede.

Tanto em Comunicação como em Educação o formato é a mensagem. Mill (2010) salienta que o modelo de EaD adotado, assíncrona ou síncrona, de aulas simultâneas e ou de materiais disponíveis para o aluno são condicionantes a definir o conjunto de diversas ações associadas e adotadas pelo professor no processo de Ensinoaprendizagem, e acrescenta: “A importância da aquisição desses saberes reflete-se no sucesso e na qualidade dos cursos virtuais" (MILL, 2010, p. 46). Inclusive presenciais, ao nosso ver.

O autor acima segue com uma preocupação que não é somente sua, sobre "a necessidade de formação profissional específica para a atuação nesta modalidade, enfocando diferentes papeis docentes" (OLIVER apud MILL, 2010, p. 46). Se queremos ensino de qualidade, precisamos de formação e professores qualificados. 
Além da qualificação para saber escolher o formato que define os diferentes papeis do docente EaD, Oliver (apud MILL, 2010, p. 47) constata que "Um dos obstáculos à concepção de cursos de formação docente para a atuação na EaD é o mapeamento ainda deficiente dos saberes e conhecimentos (gerais e particulares) necessários à atuação desses profissionais”. Uma das soluções apontadas por Mill (2010) para este problema é deixar que os próprios professores caracterizem essa deficiência e sugere formar um currículo acadêmico a partir do que dizem os professores após a experiência em 'estúdios' EaD.

Quanto a nós, além das considerações já elencadas, vimos insistindo em um caminho de diálogo entre as áreas da Educação e da Comunicação. Acreditamos que seja um diálogo necessário para a descoberta de saídas a esta problemática, sobre quais os saberes, quais os conhecimentos, quais as competências e as habilidades desses profissionais, não somente dos professores, mas, destacamos, dos técnicos, produtores e diretores, designers e comunicadores, todos precisam saber conciliar suas áreas, a fim de não operarem apenas no modo profissional ou técnico estanque.

Porém, se é verdade, como se referiu Tardif (apud MILL, 2010, p. 49) que "muitos conhecimentos necessários à docência são de natureza experiencial”, que isto valha então para todos. Eis mais um motivo para a troca de saberes e de experiências em ambas as áreas. Necessitamos conhecer melhor o papel da Comunicação e das mídias na história da Educação, em como a Comunicação e suas Teorias, seus meios e suas metodologias contribuíram no processo educacional.

Desde que a Educação é usada para capacitar ao mercado de trabalho, ela se identifica sobremaneira com os meios de produção, com a indústria cultural, com os fundamentos da Comunicação Social, das Tecnologias da Informação e porque não dizer com as correntes teóricas do Marketing e Publicidade e Propaganda. Essas áreas estão cada vez mais presentes na escola. Essa percepção deve estar na base das licenciaturas, como supõem as especialistas Silva e Cavalcanti (2008, p. 2):

Assim, considera-se que a adequação do ambiente acadêmico ao novo paradigma educacional, trazido à tona pela EAD, perpassa pela formação de um profissional capacitado a utilizar as tecnologias informacionais aplicando-as para resolução de problemas e apto a utilizá-las de forma a propiciar a mediação necessária ao processo de ensino-aprendizagem, fatores estes totalmente relacionados e dependentes da formação inicial, bem como da experiência profissional dos docentes envolvidos. 
Sobretudo ao professor urge aprender, desenvolver e aplicar competências e habilidades que não podem ser apenas direcionadas aos alunos matriculados. Logo, o Projeto Político Pedagógico de uma instituição de ensino que ignore a capacitação do professor nessas áreas correrá o risco de prejudicar os seus objetivos pedagógicos, didáticos, econômicos, inclusive de execução do Plano de Curso. Não obstante o professor tenha igualmente que se preocupar com a autoformação continuada e, admitamos, haja muito o que aprender com os apresentadores e comunicadores profissionais, sob pena dos mesmos prejuízos.

Reconhecemos, vale um estudo mais aprofundado sobre quais são essas competências que o professor EaD deve apresentar e desenvolver ao longo do seu desempenho. Quiçá algum profissional da comunicação desempenhe tão bem esse papel, vez que estamos falando de um ambiente que conhece, sobretudo se licenciado antes na área onde ministraria.

Esclarecemos, não invertemos os papeis, ou que todo comunicador se torne um profissional do ensino, mas que quem ensina com mídias precisa saber usá-las. Até porque a formação do professor $\mathrm{EaD}$, e cada vez mais a sua autoformação, é uma autoformatação.

O uso das tecnologias, seus modos de fazer, são incorporados pelo professor e mudam a sua maneira de pensar e agir. Seja o professor tutor, seja o conteudista, o professor que ingressa uma aula a distância incorpora, de certa maneira, o perfil do comunicador e do apresentador, seja gravando vídeoaulas, seja produzindo sonoras para podcast e rádio.

Chamamos a atenção daqueles que fazem a $\mathrm{EaD}$ para o fenômeno que não mais nos espreita ou se avizinha, mas já está aí. A Comunicação ingressou na Educação. Designers e produtores trabalham ensinando professores e pedagogos, e vice-versa, como a nova aula pode ser ministrada. Aqui já se descortina outro fator que interferirá na matriz curricular de diversos cursos, o ingresso de disciplinas pedagógicas não apenas nas licenciaturas e de disciplinas da Comunicação e das Tecnologias da Informação, entre outras, teóricas e práticas, nas licenciaturas. Ao que nos parece, a EaD se tornou o vértice da Educação.

Uma vez que a Educação e a Comunicação são os meios mais antigos pelos quais a sociedade foi formatada ao longo das Eras, seja econômica, política, religiosa ou filosoficamente, a $\mathrm{EaD}$ conseguiu reunir essas duas forças da informação e tem 
modificado a maneira de lecionar. Mesmo o ensino presencial usa, de alguma maneira, recursos não presenciais, migrando à hibridez, aderindo a recursos que estendem a aula além das paredes.

No ritmo em que vamos, as ofertas e facilidades de cursos a Distância explodem no mercado educacional e o novo professor, para a nova aula, precisa estar mais competente às interatividades e acessibilidades da Web, sua grande sala, praça ou lugar do ócio, nos moldes gregos da Paideia e da educação individualizada/personalizada.

\section{Professores hipermidiáticos}

É preciso salientar que tanto a individualização quanto a personalização do ensino seguem a noção básica de percepção, linguagem e satisfação. Sobre isto Santaella (2013) fala do efeito das mídias em seus usuários a partir da multiplicação crescente de linguagens humanas, sobretudo após o advento da fotografia, por sua vez incrementada no fotojornalismo e depois pelo cinema, rádio, televisão, que foram se incorporando nas linguagens mais tradicionais como o teatro, a dança, a música, as artes visuais e a literatura.

Assim, amparada pela semiótica, Santaella (2013, p. 246) constata que essas linguagens ficavam "ou sob o domínio do verbal ou do visual ou do sonoro ou, ainda, de mistura entre eles". A sua hipótese é de que há apenas três matrizes de linguagem e pensamento, das quais se originam as demais linguagens e processos sígnicos.

Em seguida à colação da autora acima, no contexto daquilo que já dissemos, acrescentese a satisfação, o gosto pessoal e a utilidade (pragmática), às motivações pelas quais o destinatário escolherá essa ou aquela matriz de linguagem. Voilá! Trazemos à lume a seguinte questão que Santaella (2013, p. 247) nos faz: "Quais são as principais implicações de tal constatação para o estado da arte da cultura digital que tantas consequências estão trazendo para os processos de ensino e aprendizagem, entre outros?"

Já chegaremos à sua resposta. Após ressaltar a priorização que as linguagens disputam, nessa produção híbrida de conteúdos digitais, a autora acima afirma estarmos na era pós-PC e que por isso eles devam ser produzidos em vista dos dispositivos móveis, com o design hipermidiático e simbiose criativa do verbal, visual e sonoro, que constituem a 
linguagem moderna. A preocupação derradeira de Santaella (2013, p. 249), e nossa, é que:

\begin{abstract}
Não se trata simplesmente de aderir à euforia da indústria produtiva, mas de avaliar, a partir de fundamentação científica adequada, o potencial interativo transformador dessas novas interfaces sensoriais com habilidade hipermídia para sua inserção nos processos de aprendizagem e aquisição de conhecimento.
\end{abstract}

Mas, se esta é a resposta da autora, ao que nos parece, ela ainda está em aberto. A expressão utilizada acima, "fundamentação científica adequada", não aponta em quais áreas poderiam travar esse diálogo fundamental e urgente entre as matrizes de linguagem.

Parece óbvio o que vamos dizer, mas isto confirma aquilo que, para nós, é a argola do gonzo, sem a qual o sino não badala, a Educação, especificamente os cursos de licenciatura não resolvem esta questão, nem encontram a tão necessária "fundamentação científica adequada", sem alinhar as suas teorias e práticas aos saberes das TIC e da Comunicação.

Estimamos que se promovam mais debates, seminários, mesas redondas, entre essas áreas, e escrevam mais artigos e livros sobre Comunicação, Pedagogia e Educação. Precisamos disso! Lemos diversos autores que contextualizam o universo cibernético na educação, mas precisamos daqueles que conseguem ir além de detectar a presença digital nos sistemas de ensino; precisamos de quem consiga incorporar prática, técnica e didática às mídias e suas plataformas, no ensino-aprendizagem, pois cada meio tem a sua linguagem e gera a uma simbiose com o usuário, desperta competências e gera habilidades (e vice-versa).

A EaD é a modalidade mais recente da educação, porém a palavra "Distância" deve ser revisada. Essa modalidade tende a redefinir todo o sistema educacional, seus sujeitos (ILHA; et all, 2009) atores e autores. Assim, consideremos a seguir o inevitável alerta de Flusser (1985, p. 15) sobre os programas dos novos aparelhos e seu relacionamento com os humanos: 
constante nem variável, mas está indelevelmente amalgamado ao aparelho.

Notamos que a preocupação com o aluno, como destinatário primaz de todo o processo $\mathrm{EaD}$, entre outros aspectos, como gestão e industrialização da aula como mercadoria escolar nos moldes do que foi o livro didático, tem descurado outro fator importante que é o perfil em construção do docente. O que notamos é que o enfoque demasiado a partir do aluno quase que desfoca esse perfil.

Sem dúvidas, há uma identidade sendo formada a partir da técnica que o professor opera. Se é verdade que o meio é a mensagem (MCLUHAN, 1969), tanto professor quanto mídia informam e educam. Se o meio é extensão do homem (MCLUHAN, 1969), igualmente o é do professor. Mas se nos tornamos aquilo que operamos (FLUSSER, 1985), então o professor também tem pensado, atuado e falado seguindo a técnica dos dispositivos que ele opera. Agora o professor não apenas pensa neles ao preparar a sua aula, pensa como se fosse um deles, pois está 'amalgamado' ao dispositivo.

Agora esses dispositivos e mídias definem a utilidade e validade de determinados enfoques do conteúdo letivo, se são possíveis ou não para aquela mídia em que o professor pretende como recurso didático. Esses não são apenas extensores multimidiáticos, são também limitadores. Fato é que a Educação precisa perguntar à Comunicação e ao Tecnólogo da Informação, ao menos de que maneira se pode transmitir este ou aquele assunto.

\section{CONSIDERAÇÕES FINAIS}

Tratamos neste artigo de alguns fatores da modalidade $\mathrm{EaD}$ que redefinem outras formas de ensinar. Elencamos algumas preocupações que, enquanto formatam a digitalização do conhecimento, configuram uma antropologia - perfil - do usuário: professor e aluno.

Do utensílio à técnica, da arte à mecânica, do digital ao virtual, homem e dispositivo, meio e extensão se fundem num compacto smart (inteligente), móbil (movente), híbrido (mesclado) e ubíquo (onipresente) que perfila tudo e a todos. 
O nosso enfoque aqui é em torno das influências da Comunicação na EaD e no perfil do educador "polidocente". Influências não apenas das TIC, mas das Teorias e técnicas da Comunicação Social, uma vez que a EaD se constrói nas salas de redação, nos estúdios de áudio e vídeo e nas suas ilhas de produção de audiovisual.

Nossa experiência, sobretudo nessas duas áreas, Educação e Comunicação Social, nos levaram a constatar que ambas se cruzam e permutam seus conhecimentos. Outrossim, se a economia, a política e a religião definiram a educação e a sociedade em suas épocas, entendemos que a atual Era digital inaugura outra dimensão do modo de educar, onde o professor e o aluno dividem o protagonismo e podem, dessa vez, lançar mão do perfil e das características dos profissionais que mais lhes auxiliem nesse processo.

Se os programadores, comunicadores e designers se inserem no processo educacional com habilidades próprias, o seu perfil pode potencializar o professor que lhe toma emprestado algumas competências. Assim o roteirista, o produtor, o diretor, o fotógrafo, o redator, o repórter, enfim, o comunicador em geral, aquele que sabe contar bem uma história e consegue recriar no imaginário do espectador a cena como se a visse, desperta os sentimentos e o interesse até a participação mais ativa no cotidiano de quem lhe dá atenção. Uma atenção intencional, porém conquistada não pela simpatia, mas por suas capacidades técnicas, pelo seu modo de saber fazer e de levar a informação.

Se as TIC e suas práticas se engendram na educação, seus práticos e profissionais também podem ingressar. Ainda que isto já aconteça, chamamos a atenção nesse artigo para o fato de que esse técnico não é o professor, mas o professor carece dessa técnica. Chega a ser bíblico: "Dai a César o que é de César!" Para dizer que a cada um compete a sua habilidade. $\mathrm{Na} \mathrm{EaD}$ não seria diferente.

Ainda mais o universo digital privilegia a personalização e a autonomia do aluno e desenvolve competências e habilidade no dinamismo do processo de educação a que se submete. Ele aprende a acessar e navegar na web. Na rede está tudo que ele precisa, de fácil e livre acesso. Isto não é diferente com o professor. Ele também está sendo 'hibidrizado' do mesmo modo. O Professor comunicador também se torna uma mídia da educação. Talvez precise incorporar outras dimensões das mídias modernas como ser transmidiático e aumentar o giro de sua exposição de conteúdo até aos 360 graus.

Estas configurações simbióticas são desafios que até mesmo as mídias convencionais enfrentam. Nem todas as plataformas e formatos são niveladas e acessíveis a todos. 
Entretanto o que as TIC atuais nos ensinam é que elas se conectam entre si e um professor conectado conecta os seus alunos. O professor EaD é um professor midiático. O que não quer dizer necessariamente das redes sociais. Embora seja uma figura pública, não precisa ser uma figura popular. Entenda-se que seu perfil comunicador não faz dele um apresentador global.

Este professor é um profissional atualizado no conteúdo e onde ele está disponível com qualidade. É um facilitador enquanto conhece caminhos nas teias da Internet. É um pesquisador e alimentador dessas fontes de informação. A sua preparação e capacitação devem ser oferecidas pelos cursos acadêmicos tanto quanto devem ser procuradas por si mesmo. Aquilo que a didática do EaD ensina aos alunos o professor aperfeiçoará em sua autoformação. Ele também habita e transita no ciberespaço e conhece o ambiente sócio-virtual. Do contrário, ignoraria o seu ambiente de trabalho.

Não importa qual seja a mídia, o professor terá que saber usar. Ele e o veículo escolhido se fundirão ao conteúdo. A mídia é a nova sala de aula, nesta nova modalidade de ensino que está redefinindo a Educação. Não são as TIC que formatam a EaD, mas este pilar, quando pensado antes delas, redefine o seu uso. Esta é a razão do ensino, sua alma, pois é partir das ideias que se definem a forma das coisas.

\section{REFERÊNCIAS}

ABED - Associação Brasileira de Educação a Distância (Org.). Censo EAD.BR: relatório analítico da aprendizagem a distância no Brasil 2016. Curitiba: InterSaberes, 2017. Disponível em:

<http://abed.org.br/censoead2016/Censo_EAD_2016_portugues.pdf> Acesso em: 01 jul. 2018.

AGAMBEN, G. O que é um dispositivo? Trad. Nilcéia Valdati. Outra travessia 5, Ilha de Santa Catarina, 2005. Disponível em:

<https://periodicos.ufsc.br/index.php/Outra/article/download/12576/11743> Acesso em: 05 dez. 2016.

BAUMAN, Z. Modernidade líquida. Rio de Janeiro: Jorge Zahar Ed., 2001 
BLUM, O. R. O Marco Civil da Internet e a Educação Digital no Brasil. In:

ABRUSIO, Juliana (Org). Educação digital. São Paulo: Editora Revista dos Tribunais, 2015. P. 175 a 190.

BRASIL. Ministério da Educação e Cultura. Secretaria de Educação a Distância.

Referências de Qualidade para a Educação Superior a Distância. Brasília, 2007.

CGI.br - Comitê Gestor da Internet no Brasil. Pesquisa sobre o uso das tecnologias de informação e comunicação nas escolas brasileiras. TIC educação 2016. Núcleo de Informação e Coordenação do Ponto BR, [editor]. -- São Paulo. 2017. Disponível em <http://cetic.br/media/docs/publicacoes/2/TIC_EDU_2016_LivroEletronico.pdf> Acesso em: 29 jun. 2018.

COSTA, A. R. F. da; AQUINO, M. de A. Industrialização do ensino e política de educação a distância. Ciência em Movimento. Ano XII, n. 26. 2011/2. Disponível em: $<$ https://www.metodista.br/revistas/revistasipa/index.php/EDH/article/viewFile/102/66> Acesso em: 30 jun. 2018.

DIAS, R.; LEITE, L. S. Educação a Distância: da Legislação ao Pedagógico. $2^{\text {a }}$ Ed. Petrópolis - RJ: Vozes, 2010.

FONTANA, H. A. Uma filosofia para a educação à distância. In: II Seminário Nacional de Filosofia e Educação - Confluências, 2006. Santa Maria/RS. Anais... Santa Maria/RS: UFSM, v.1, 2006. Disponível em: <http://coral.ufsm.br/gpforma/2senafe/PDF/049e4.pdf> Acesso em 30 jun. 2018.

FLUSSER, V. Filosofia da Caixa Preta - Ensaios para uma futura filosofia da fotografia. São Paulo: Ed. Hucitec, 1985.

GABRIEL, M. Educ@r: A (r)evolução digital na educação. São Paulo: Saraiva, 2013. ILHA, F. R. da S., BAPTAGLIN, L. A., SCHWAAB, S. G., DRABCH, N. P., PINTO, D. G., OLIVEIRA, O. S. de. Educação a distância: a aprendizagem de professores, tutores e alunos no desenvolvimento do trabalho educativo. In: IX Congresso Nacional de Educação - EDUCERE, 2009. Paraná. Anais... Paraná: PUCPR, 2009. Disponível 
em: <http://educere.bruc.com.br/arquivo/pdf2009/2514_1703.pdf> Acesso em: 30 jun. 2018.

KEEN, A. Vertigem Digital: Por que as redes sociais estão nos dividindo, diminuindo e desorientando; Tradução Alexander Martins. Rio de Janeiro: Zahar, 2012.

LÉVY, P. As tecnologias da inteligência: o futuro do pensamento na era informática. Lisboa: Instituto. Piaget, 1990.

MCLUHAN, M. Os Meios de Comunicação como Extensão do Homem. São Paulo: Editora Cultrix, 1969.

MCLUHAN, M A Galáxia de Gutenberg: a formação do homem tipográfico. Trad. Leônidas Gontijo de Carvalho e Anísio Teixeira. São Paulo: Editora Nacional, Editora da USP, 1972. Disponível em: http://docslide.com.br/documents/marshall-mcluhan-agalaxia-de-gutenberg.html. Acesso em: 04 jun. 2016.

MILL, D.; RIBEIRO, L. R. de C.; OLIVEIRA, M. R. G. A Docência Virtual Versus Presencial Sob a Ótica dos Professores. In: Polidocência na Educação a Distância: múltiplos enfoques. São Carlos - SP: EdUFSCar, 2010. Cap. 3. P. 41 a 57.

PARISER, E. O Filtro Invisível: o que a internet está escondendo de você. Tradução Diego Alfaro. Rio de Janeiro: Zahar, 2012.

PAVLIK, J. V. Ubiquidade: O $7^{\circ}$ princípio do jornalismo na era digital. In:

CANAVILHAS, J. (org). Webjornalismo: 7 características que marcam a diferença. Covilhã: UBI, LabCom, Livros LabCom, 2014. (ebook) Disponível em: < http://www.labcom-ifp.ubi.pt/ficheiros/20141204201404_webjornalismo_jcanavilhas.pdf> Acesso em: 30 jun. 2018.

PESARINI, S. Qual é o Perfil dos Professores para Trabalhar na Modalidade a Distância? Revista eletrônica Administração \& Ciências Contábeis. Curitiba - PR: Faculdade Opet. n $^{\circ} 5$ Jan-Jul 2011/1. Disponível em: http://www.opet.com.br/faculdade/revista-cc-adm/pdf/n5/QUAL-E-O-PERFIL-DOS- 
PROFESSORES-PARA-TRABALHAR-NA-MODALIDADE-A-DISTANCIA.pdf. Acesso em 31 maio 2016.

SANTAELLA, L. Comunicação Ubíqua: Repercussão na cultura e na educação. São Paulo: Editora Paulus, 2013. (Coleção Comunicação).

SILVA, K. C.; CAVALCANTI, P. S. A importância do perfil docente na mediação em EAD. In: $14^{\circ}$ CIAED - Congresso Internacional de ABED de Educação a Distância. 2008. Santos/SP. Anais... Santos/SP, 2008. Disponível em: http://www.abed.org.br/congresso2008/tc/5112008115230pm.pdf. Acesso em: 31 maio 2016.

WERTHEIM, M. Uma História do Espaço de Dante à Internet. Tradução Maria Luiza X. de A. Borges. Rio de Janeiro: Jorge Zahar Editor. 2001.

GOUVEIA, F. R.; CESAR, M. O Professor EAD: Um Perfil. In: 15 CIAED Congresso Internacional de ABED de Educação a Distância. 2009. Fortaleza/CE. Anais... Fortaleza/CE, 2009. Disponível em:

http://www.abed.org.br/congresso2009/CD/trabalhos/1552009171801.pdf. Acesso em: 31 maio 2016.

ZAVAM, A Da Escrita à Revisão: o processo de produção de material para EaD. In: ARAUJO, J.; NUKÁCIA, A. (Org.). EAD em Tela: Docência, Ensino e Ferramentas Digitais. Campinas - SP: Editora Pontes. 2013. P. 209 - 237. 


\section{Adeilton Santana Nogueira}

Mestre em Educação (linha 1 - Educação e Comunicação), Universidade Tiradentes -

UNIT/SE. Pesquisador no Grupo de Estudos em Tecnologias da Informação e Cibercultura - UNIT/GETIC

\section{Andrea Karla Nunes}

Mestrado e Doutorado em Educação da Universidade Tiradentes, da linha 1 - Educação e

Comunicação - PPED - Universidade Tiradentes - UNIT - SE

\section{José Gomes da Silva}

Doutor e Mestre em Educação pela Universidade de Salamanca (ESP). Professor investigador na Universidade Tiradentes - UNIT - PNPD.

Artigo recebido em 30/07/2018

Aceito para publicação em 24/07/2019

Para citar este trabalho:

NOGUEIRA, Adeilton Santana; NUNES, Andrea Karla; SILVA, José

Gomes da . EDUCAÇÃO A DISTÂNCIA E COMUNICAÇÃO:

PERCEPÇÕES DA FORMATAÇÃO DO PERFIL DOCENTE E

DISCENTE. Revista Paidéi@. Vol.11- Número 20- Julho - 2019 Disponível em:

http://periodicos.unimesvirtual.com.br/index.php/paideia/index 